\title{
Unmet needs of bipolar disorder patients
}

This article was published in the following Dove Press journal:

Neuropsychiatric Disease and Treatment

24 June 2016

Number of times this article has been viewed

\author{
Miroslav Hajda' \\ Jan Prasko' \\ Klara Latalova' \\ Radovan Hruby ${ }^{2}$ \\ Marie Ociskova' \\ Michaela Holubova ${ }^{1,3}$ \\ Dana Kamaradova' \\ Barbora Mainerova' \\ 'Department of Psychiatry, Faculty \\ of Medicine and Dentistry, Palacky \\ University Olomouc, University \\ Hospital Olomouc, Olomouc, Czech \\ Republic; ${ }^{2}$ Outpatient Psychiatric \\ Department, Martin, Slovak Republic; \\ ${ }^{3}$ Department of Psychiatry, Regional \\ Hospital Liberec, Liberec, Czech \\ Republic
}

Background: Bipolar disorder (BD) is a serious mental illness with adverse impact on the lives of the patients and their caregivers. BD is associated with many limitations in personal and interpersonal functioning and restricts the patients' ability to use their potential capabilities fully. Bipolar patients long to live meaningful lives, but this goal is hard to achieve for those with poor insight. With progress and humanization of society, the issue of patients' needs became an important topic. The objective of the paper is to provide the up-to-date data on the unmet needs of BD patients and their caregivers.

Methods: A systematic computerized examination of MEDLINE publications from 1970 to 2015, via the keywords "bipolar disorder", "mania", "bipolar depression", and "unmet needs", was performed.

Results: Patients' needs may differ in various stages of the disorder and may have different origin and goals. Thus, we divided them into five groups relating to their nature: those connected with symptoms, treatment, quality of life, family, and pharmacotherapy. We suggested several implications of these needs for pharmacotherapy and psychotherapy.

Conclusion: Trying to follow patients' needs may be a crucial point in the treatment of BD patients. However, many needs remain unmet due to both medical and social factors.

Keywords: bipolar disorder, unmet needs, stigma, treatment, medication, quality of life, family, psychotherapy

\section{Introduction}

Individuals with bipolar disorder (BD) suffer from a multifaceted, difficult, and somewhat unpredictable course of their disease. It is characterized by substantial, and from time to time, particularly handicapped manic or depressive symptoms. Thus, even patients who follow treatment advice are still at a high relapse risk. Repeated relapses and rehospitalizations are main distresses, indicating a "downward spiral" of declined functioning and greater dependency on support and care by others. ${ }^{1}$

In the last decades, an increasing attentiveness to human rights and democratic sensibility has given an impulse to the enhancement of the users of mental health care. Both patients and their caregivers began to identify their needs and focused more on their health care utilization. This changed the traditional paternalistic physician-patient relationship by empowering the patients. The progress of the relationship between the providers and consumers of the mental health care has also led to increased attention to human rights. The debate has focused on the requirement for respect and freedom and the so-called existential requests, such as the need to have a meaningful life, and the necessity of spirituality. ${ }^{2}$ While such needs are important for all individuals, regardless of their health status, they are particularly significant for patients with severe medical disorders, including patients suffering from severe mental illness. Thus, the topic of fundamental human needs takes its place also in patients with BD. The aim of this article
Correspondence: Jan Prasko

Department of Psychiatry, Faculty of Medicine and Dentistry, Palacky University Olomouc, University Hospital Olomouc, IP Pavlova 6, 77520 Olomouc, Czech Republic

Tel +4206034l4930

Email praskojan@seznam.cz
Neuropsychiatric Disease and Treatment 2016:12 I56I-1570

Dovepress if in 8

http://dx.doi.org/10.2147NDT.S105728 (c) (1) (5) 2016 Hajda et al. This work is published and licensed by Dove Medical Press Limited. The full terms of this license are available at https://www.dovepress.com/terms.php C. hereby accept the Terms. Non-commercial uses of the work are permitted without any further permission from Dove Medical Press Limited, provided the work is properly attributed. For permission for commercial use of this work, please see paragraphs 4.2 and 5 of our Terms (https://www.dovepress.com/terms.php). 
was to explore recent scientific facts regarding the needs of the individuals with BD. The sense of our review is to show the broad concept of patients' needs because of the complexity of problems of patients with BD. We focus not only on the needs connected with the diagnosis and treatment but also on the psychosocial well-being and quality of life.

\section{Methods}

Articles were obtained by using PubMed MEDLINE by systematic searching and extracting papers published in the years between 1970 and 2015. We performed systematic searches using the terms "bipolar disorder", "mania", and "bipolar depression", in successive combination with "unmet needs". The search was limited to the English language. There were both research studies and reviews. The subjects had to be adults and had to be diagnosed with BD. Furthermore, the papers included had to have been published in peer-reviewed journals; they could be explicit data or reviews on the relevant topic. Excluded were books, book chapters, commentaries, editorials, letters, and dissertations. We utilized a flow diagram to summarize the total number of screened papers and the number of those included in the review process. The procedure for the inclusion of articles is shown in Figure 1.

\section{Results}

We divided the needs into four categories, according to their common elements: needs connected with the symptoms, symptoms' control, quality of life, and the family. Within these categories, we described especially those patients' needs that remain both a significant problem in clinical practice and important for patients. In each category, we also identify particular needs, which are more or less met.

\section{Needs connected with the symptoms}

A considerable part of the unmet needs is related to the symptoms of the BD. The patients may express worries about enduring symptoms and have trouble in handling them. The needs related to the symptoms may differ at various stages of the illness. They are often linked to the lack of insight, information, and support from family or the medical staff., 3,4 Symptoms of the disease can suppress some needs or potentiate others, depending on the stage of the illness.

\section{Specific needs during hypomania and mania}

In mania, the patients' needs often tend to be foremost at the expense of others. ${ }^{5}$ In hypomania and mania, patients, for example, have a lower need for sleep and eating. Social needs such as contact with others and finding potential intimate short-term relationships are increased, social inhibitions are reduced, and the need for increased activity is evident.

During the (hypo)mania, the long-term patients' needs are the alleviation and elimination of the symptoms of the illness as well as proper treatment. To satisfy these needs, it is necessary to seek the treatment and adhere to it. However, the need for the treatment is mostly in conflict with the current (hypo) manic mood, thinking, and behavior. The elevated mood discourages patients from seeking stabilizing treatment. Still, some patients, who repeatedly experienced mania in the past, may visit a specialist at the very beginning of hypomania. To do this, they must have established a sufficient level of insight and trust their psychiatrist. ${ }^{6,7}$ However, even in these rather rare situations, they are frequently ambivalent toward the treatment. They would like to maintain a good mood and increased self-confidence, but they are afraid of the

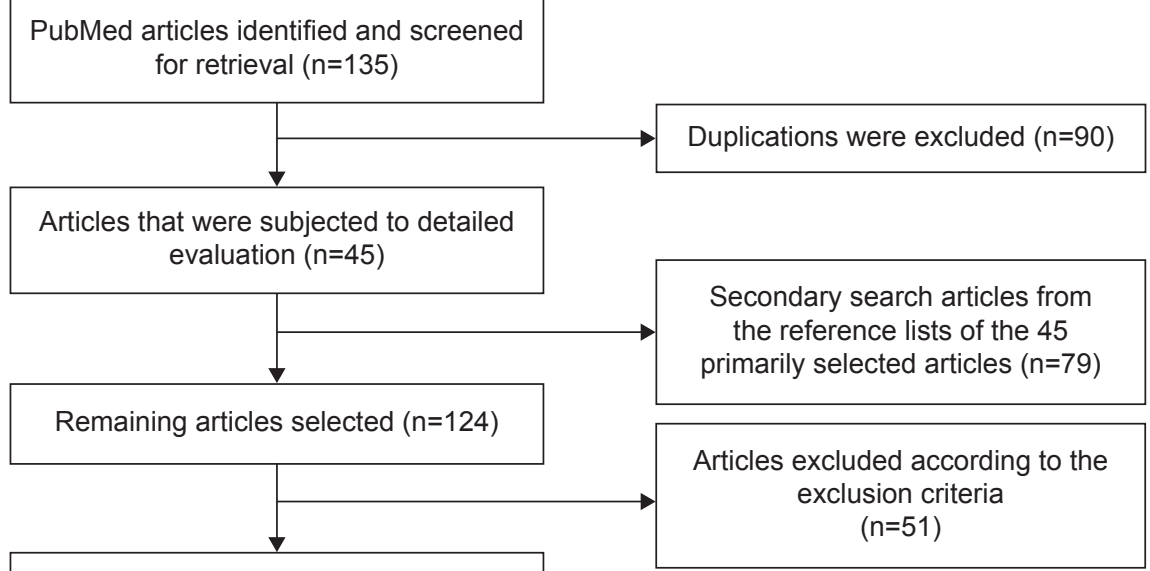

Articles included in the article $(n=73)$

Figure I Summary of the process of the article selection. 
consequences. For psychiatrists, it is important to debate the pluses and minuses of elevated mood and utility of "normal mood" with the patients.

In summary, the most important unmet need in hypomanic and manic states is encouraging acceptance and undergoing of therapy.

\section{Specific needs during depression}

Depression is one of the biggest causes of disability in BD and, in comparison with mania, has not as many developed standardized guidelines for the treatment. ${ }^{8}$ Episodes of depression are usually more frequent, they last longer than manias, and the patients feel worse and have reduced selfconfidence. The treatment is further hindered by feelings of inadequacy and worthlessness.

Kulkarni et $\mathrm{al}^{9}$ in their 2-year study focused on relapses and remissions in bipolar I disorder (BD-I) patients. Depressive relapses were twice as frequent as relapses of mania. They also found out that remission from symptomatic mania was more prevalent (92\%) than remission from syndromal depression (76.5\%). ${ }^{9}$ Judd et $\mathrm{al}^{10}{ }^{10}$ supported these outcomes in a long-term study of BD-I. Their results showed that patients remain symptomatically ill for $47 \%$ of the time, and they mostly suffer from depressive symptoms.

The patients' needs during the depressive episode tend to be similar to the needs of the family and the psychiatrist since they all want to make the symptoms disappear. ${ }^{11}$ Additionally, the patients need from others tolerance, empathy, enhanced feelings of hope for improvement, safety, help with decreasing feelings of guilt, and endurance that they lack. ${ }^{12}$

Masand and Tracy ${ }^{13}$ recognized that, despite the level of treatment, the greatest unmet need of the bipolar patients is the problem of the treatment of bipolar depression (identified by $33.3 \%$ of patients), with treatment access, treatment affordability, and relapse prevention being identified by about one in five respondents. The result of Leibenluft et $\mathrm{al}^{14}$ showed that patients are concerned the most about decisions on treatment location (inpatient or outpatient) as well as decisions about pharmacological or psychotherapeutic treatment.

In summary, the most common unmet need in the depressive stage is early recognition of depression and the encouragement of the decision to seek treatment, and in the case of severe depression acceptance of eventual hospitalization.

\section{Needs during remission}

Established or emerging remission is accompanied by favorable life status and improved quality of life., ${ }^{915}$ The basic needs during remission are the maintenance of well-being, mental illness not being experienced as a stigma, return to employment and family life, and decreasing the fear of relapse. For many patients with this stage of disease, it is important to improve self-esteem and decrease self-stigma. ${ }^{16-18}$ No less important are also adherence to treatment, regular use of medication, and regular follow-up by the treating psychiatrist.

Although patients might consider medication as being useful, they may still refuse it as a way to achieve at least some independence and control over their lives. ${ }^{19}$ Sometimes patients without sufficient experience may think that there is no need for medication because they are feeling better. However, many patients live more with the worries of relapse, with the subsequent decrease of maintaining quality relationships and the inability to keep their professional status.

In summary, the most significant unmet need during remission is medication without adverse effects.

\section{Needs and residual symptoms}

Despite substantial progress in pharmacotherapy for BD, many patients remain symptomatic between episodes. ${ }^{20}$ Regardless of many existing types of treatment, a considerable number of patients with $\mathrm{BD}$ experience only partial symptoms remission or symptoms recurrence.

Bipolar patients often suffer from severe symptoms that make everyday life difficult. After a resolved acute episode, following treatment could be a challenging time for the involvement of patients in ordinary life. Residual symptoms can restrict the capacity to contact and have benefits from community services. ${ }^{21}$ The patients recognize unmet needs connected to the illness. Families recognize distresses associated with the absence of improvement of the patient at the time. Many patients and families do not fully understand the aims of follow-up or long-term preventive care.

In summary, the most common unmet need in patients with residual symptoms is a lack of the efficacy of the available medication and need for a wider spectrum of easily available psychosocial intervention.

\section{Needs during relapse}

Despite the continual adherence to drug schedules in many patients, the probability of relapse after 5 years of follow-up was as high as $73 \%{ }^{22}$ Life stressors were identified to be the most common cause of relapse (43.2\% of relapses). ${ }^{13}$

Significant sleep disturbance also accompanies BD. Reduced sleep is recognized to be connected with substantial adverse psychosocial, job-related, economic, and health effects. ${ }^{23}$ An analysis of eleven research studies with 
631 BD patients has shown that problems with sleep were the most frequent in prodromes of mania (77\% of patients) and the sixth most frequent prodrome of depression episodes (24\% of patients). ${ }^{24}$ Some data indicate that disturbances of sleep are associated with relapse in BD. ${ }^{25}$ There is a decreased need for sleep during episodes of mania. During the depression, bipolar patients usually have problems with decreased or increased sleep. Unpredictably, recent data suggest that troubles with sleep remain even when patients are in remission. ${ }^{26,27}$ The time of remission is also imperative because the patients suffer from other substantial symptomatology and impairments, including mood dysregulation. ${ }^{20}$ There is evidence that education about early recognition of manic relapse signs and seeking early treatment leads to a prolonged period until the next episode of mania, improvement in work-related adjustment, social functioning, and well-being. ${ }^{28}$ Malkoff-Schwartz et al ${ }^{29}$ studied that topic and hypothesized that stressful life events linked with social rhythm disruption would frequently be detected in prodromal stages before a BD episode.

Several studies showed that hypersomnia prevails in patients with bipolar rather than in patients with unipolar depression. ${ }^{30,31}$ Similarly, hypersomnia is mostly recurs through distinct episodes of bipolar depression. ${ }^{14,32}$ Manipulations of the circadian rhythms have been used to enhance sleep deprivation antidepressant efficacy in patients with BD. ${ }^{33}$

In summary, the most common unmet needs connected with the relapse are early recognition of the warning signs of relapse, treatment of sleep disturbances, modification of lifestyle to decrease the probability of life stress, and rapid acting medication.

\section{Patient perception of health status}

Most of the participants in the study of Shattell et $\mathrm{al}^{34}$ described adverse experiences with the health care professionals and system. Somatic illnesses were ignored when symptoms were qualified as related to the mental health.

In summary, many patients perceived lack of attention and understanding by the health care expert. Some patients complained about enormous efforts to achieve health care for somatic symptoms.

\section{Stigmatization}

There are various prejudgments about psychiatric patients in the community. A substantial number of BD patients have to cope with stigma-related behavior by lay peoples as well as health care staff. ${ }^{34}$ The patients attribute this disorder to not being seen as a human being. These distorted beliefs not only of society but also of patients contribute considerably to the shaping of attitudes toward stigma to which the psychiatric patients are daily exposed. Patients treated in psychiatry are stereotypically perceived as dangerous, illogical, and aggressive. ${ }^{35}$ This leads to public reservations and small opportunities in life. ${ }^{36}$ Patients with BD also tend to fear intensely rejection. These patients seek medical services relatively late or not at all. If they have sufficient insight, they may perceive each diagnosed symptom of $\mathrm{BD}$ as a painful stigma that pulls down hope for progress in their condition and their self-esteem.

The stigmatization itself usually takes the form of interpersonal coldness or distance for the distressed person. The distancing behavior could be primarily realized in close intimate relationships (spouse, family, and friends) and job relationships. The rejection that originates from the stereotyped understanding of psychiatric disorders also happens in circumstances in which the person acts completely normal. Circumstances at the job and in the family may be somewhat parallel. The patients can be markedly observed after discharge; people around the patient behave vigilantly, review his or her behavior, and relate it to the labels they have. ${ }^{18}$ Each of the unexpected activities, linked to the illness or not, is directly qualified as the indication of the malady.

Self-stigma is accompanied by lower self-esteem. ${ }^{37}$ There is confirmation for a positive correlation between the patient's evaluation of the therapy relation and his/her grade of selfesteem in early psychosis interventions. ${ }^{38}$ In summary, the most important unmet needs connected with stigmatization are the change of public opinions to the people with mental illnesses and the programs oriented to the decrease of the self-stigmatization.

\section{Needs connected with the symptoms control}

There are many needs associated with the control of the symptoms. The basic needs are related to the proper time of treatment intervention, which is helpful, rapidly effective, not complicated, without many side effects and harmless, lacking the need for hospitalizations, and not interrupting the everyday routine.

Various unmet needs related to pharmacological treatment such as, 1) to develop more rapid-acting treatments with better side-effect profiles; 2) to identify drugs for the adequate management of resistant bipolar depression, resistant mania, rapid cycling, and mixed states; and 3) to determine pharmacological treatments targeting the cognitive deficits in $\mathrm{BD}$, are important tasks for the future. 
All these qualities can rarely be achieved, but it is important to do the best. To provide the patients with BD accurate, evidence-based health care, recommendations have been established; for instance, the American Psychiatric Association, ${ }^{39}$ Canmat guidelines, ${ }^{40}$ and also Algorithms of Czech Psychiatric Association. ${ }^{41}$ These guiding principles are designed mainly for the drug, biological treatments, and psychotherapy. ${ }^{42}$

In the qualitative study of Sajatovic et al, ${ }^{43}$ just over one-third of bipolar patients experienced a lack of relevant information about BD. Most of the patients indicated difficulties remembering to take drugs and sometimes were not sure about the usefulness of taking medications. Others described how ambivalence concerning the importance of drugs and overlooking taking medications both reinforced the nonadherence. Some patients found it difficult to remember a twice-daily drug regimen. Patients faced a multiplicity of difficulties in taking drugs, together with concerns that they had an unnecessary number of prescribed medications, very high doses of medications, and access difficulties plus being unable to pay for drugs or get transportation to appointments. Troublesome side effects involved multiple somatic complaints or specific complications such as tiredness.

\section{Barriers to help-seeking}

More research concerning of mental health services will need to identify actionable barriers that prevent access to care. Very often, treatment is started with a significant delay, which prolongs the suffering of the patient.

According to a Dutch study, ${ }^{3}$ spouses of people with BD described mental health services as unreachable, and the examination of professional support has been described by families as an additional stressor, according to other studies. ${ }^{44,45}$ The results of the study of Van der Voort et $\mathrm{al}^{3}$ indicate that psychiatry services do not function optimally when they move toward evaluating the needs of caregivers, deliver the information, or create the opportunities for appropriate support.

Sometimes treatment is initiated in a derogatory way (patients are brought to the hospital by the police in handcuffs), relatives curse the patients, and so on. The acute admission to hospital may occur in a painful or traumatic way that complicates the collaboration with the treatment.

Important factors influencing help-seeking include the family environment and the view of household members of the need for the treatment of mental health problems, attitudes toward medication use, patient's self-image and the desire to manage everything without outside assistance, insight into symptoms of mental illness, awareness of the need to take medication, previous experience and myths regarding the treatment of mental illness in society, and also the stigma of mental illness.

\section{Needs during hospitalization}

Patients need to orient themselves during hospitalization; this will help them to increase the sense of security. Adequate treatment is necessary as well as sufficient contact with other patients met during the hospitalization. It is also crucial for the whole medical staff to exhibit respect for the patient's condition. Despite the restrictions, it is necessary to provide patients the maximal possible degree of freedom. Positive interest and understanding are essential. Last but not least, it is important to reward patients appropriately for independence, create friendly but sufficient restrictions in case of suicidality or aggression, and also help the patients to solve urgent social problems. Sometimes it is necessary to calm, graciously, family members.

\section{Needs in follow-up care}

At the time of deinstitutionalization, patients with $\mathrm{BD}$ were confronted with the complications of existing in the community, and their psychiatric managing had to adapt. As psychiatric services enlarged in availability and diversity, the organization has become more service-oriented. In addition to the previously recognized clinical features, simplifying the right of entry to social contacts, housing, and jobs was included in the management of patients with BD. ${ }^{46}$

Progressively, the inpatient treatment for an episode of $\mathrm{BD}$ is restricted to days rather than months. For some people, it means that residual symptoms can remain and negatively affect their capabilities to adapt for day-to-day living in the community. Next episodes and new hospitalizations are principal characteristics of the disease course of BD patients. Relapse rates are high and range from $40 \%$ to $80 \%$ in 1 year after hospitalization. ${ }^{47}$ The early post-discharge stage of the management can be critical for long-term adjustments in the community setting. ${ }^{46}$ Explanations for these early relapses are uncertain but could be associated with the distress connected with going back into the community after intensive inpatient treatment. The management of $\mathrm{BD}$ patients can be enriched if it is based on a broad knowledge of the patients' experiences of transition from hospital to community, as well as on the related needs that they recognize as unmet. The first days after discharge from inpatient treatment facilities can be an especially fragile time for bipolar patients, even with arranged follow-up care transitioning. 
The good therapeutic relation is important for the start of the successful pharmacohological and psychotherapeutic treatment outcome. The relation between therapeutic relation and treatment outcome is a strong result of the psychotherapy investigations. ${ }^{48}$ The management of the therapeutic relation in patients with $\mathrm{BD}$ has various demands. The best framework, ${ }^{19}$ 1) assimilates current scientific results of the therapeutic relation, 2) tailors therapeutic activity for each patient personally, both proactively and reactively, 3 ) uses the results of basic science, and 4) is well-matched with the variety of strategies (eg, pharmacological and psychotherapeutic).

\section{Adherence}

Medication is a basis of treatment for $\mathrm{BD}$ patients. However, there is ubiquitous nonadherence with recommended treatment, which leads to adverse consequences, such as recurrence or relapse of the disorder. ${ }^{39,49}$ The significant rate of medication discontinuation and the associated treatment complications could indicate unmet needs for patients with BD. There are a lack of studies focused especially on nonadherence in $\mathrm{BD}$, and only a few studies have additionally focused on individuals' perceptions of the disorder and drug treatment adherence..$^{50,51}$

Medication refusal might completely saturate need of the patients autonomy. ${ }^{48}$ Nevertheless, another BD patient might reject drugs to gain extra meetings with a psychiatrist or to develop a better connection with family, to complete his/her need for attachment. Moreover, many patients can simply want to avoid adverse side effects. ${ }^{19}$ Thus, one difficult behavior can work for very diverse motivational reasons. Also, difficult behavior can be multiply determined (eg, serving autonomy and affiliation). Nonadherent patients are less likely to be included in research studies, which restricts the chances to develop evidence-based methods for enhancement in adherence. Patient-focused qualitative approaches may lead to many different but also valuable insights into patients' beliefs about therapy. ${ }^{52}$ Without clinicians understanding why a patient is adherent or not to the prescribed drugs, it is hard to prepare strategies that address nonadherence.

Quantitative analysis in the study of Sajatovic et a ${ }^{43}$ has shown that problems with medication schedules, worries about medication adverse effects, and denial of the psychiatric illness or its severity were the most significant influences on the negative beliefs toward medication of BD patients. Qualitative findings indicated that nonadherence was substantially influenced by side effects such as drowsiness and weight gain, as well as by belief that medications were not needed.
The study of Sajatovic et al ${ }^{43}$ also showed that overlooking taking the drugs was the main self-reported cause for nonadherence $(55 \%)$. The qualitative evaluation indicated that adverse effects experienced by patients $(20 \%)$ are the second highest frequent cause for nonadherence. Another cause involved reluctance to use the drugs for a lifetime and wishing to experience symptoms of mania.

A lot of nonadherent BD patients did not perceive that they have owned control of their disease. ${ }^{53}$ While most patients experienced drugs as being useful, with direct effects on symptoms, functioning, and anxiety levels, this was countered by worries about possible difficulties and not having control over their life. Stimulating positive views that encourage suitable pharmacotherapy, supporting BD patients to have control over the disorder, and allaying mistaken health opinions through psychosocial approaches, could increase treatment collaboration among persons who feel helpless about the disease. ${ }^{12,54}$ Zeber et a ${ }^{55}$ described that drug adherence is associated with the therapeutic relationship since better adherence was observed when psychiatrists repeatedly evaluated improvement and encouraged communication.

In a survey of psychiatrists, Chengappa and Williams ${ }^{8}$ also found effective treatment options to be a major barrier to the efficient management of BD. Clinically effective treatments are also thought to lower the burden on caregivers of individuals with $\mathrm{BD} .56$

\section{Needs connected with the quality of life}

This category could be demarcated as any apprehensions, worries, or difficulties that patients recognized as not related to a particular symptom of illness but adversely affecting the capability to integrate into the community, and/or decreasing the quality of life. Occupation, finance, and other daily events are examples of the distress articulated by the BD patients in the qualitative study of Gerson and Rose. ${ }^{21}$

Many BD patients coped with the problems of abuse (sexual, physical, and emotional), divorce, distancing from family, loss of children, rape, and homelessness. ${ }^{34}$

The disorder interferes with life experiences of many patients, who reported interference with study plans, interpersonal relationships, career, and the establishment of their own family. ${ }^{34}$

\section{Needs connected with the family}

This category could be distinct from the means in which family members or close relatives be of assistance to the patient to reintegrate into society and to manage their illness.

Family members have grown to be more central in care. The investigation indicates that providing support to people 
who take care of patients with severe psychiatric diseases should be a relevant part of the management. ${ }^{57}$

Support comes in the form of help with specific tasks such as handling money or fulfilling prescriptions. In the qualitative study of Gerson and Rose, ${ }^{21}$ patients also reported about the assistance of family supporters who visited them while they were in the hospital. Finally, patients also described support as being satisfied in speaking with family members about their diseases. Perlick et $\mathrm{al}^{7}$ and Van der Voort et $\mathrm{al}^{3}$ showed that most of the caring persons feel a modest level of burden, not only throughout the episodes of depression or mania but also constantly. This problem is linked to symptomatic behavior, reduced efficiency in responsibilities the individual being cared for, and adverse costs for family and household. In all three previous studies, the link seems to be concerning how families evaluate the circumstances and the burden they live through. ${ }^{5,58-60}$ The belief that people with BD are principally capable of controlling their behavior connected with BD has been recognized to be linked to the higher intensities of problems and disappointment with the relationship. ${ }^{6}$

Family coping styles can be acknowledged and used to organize strategies to decrease the burden on the family as they support the treatment of the patient symptoms and increase the adherence to treatment. ${ }^{61}$

\section{Implications for pharmacotherapy}

The ability of the psychiatrist to recognize the psychiatric patient needs reduces the risk of missing of various problems, for instance, arbitrary withdrawal of medication. Unpleasant cycles of the difficult patient and problematic therapist behaviors (eg, the psychiatrist impels the patient to be cooperating in using drugs, the patient refuses drugs to experience himself as independent).

\section{Side effects}

In a study by McIntyre, ${ }^{62}$ UNITE Internet survey recruited patients from eleven countries, and a total of 5,074 participants responded (1,155 individuals with schizophrenia and 1,300 with BD were self-identified). Psychiatrists were acknowledged as the people primarily responsible for patients' drug prescriptions and observation of both psychological and somatic health. The bulk of respondents in both groups had been receiving medication for $>5$ years. Weight increase was the most frequently cited side effect related to the administration of drugs. Moreover, weight gain was also recognized as a contributing factor to general medical health (eg, diabetes mellitus) and as a detractor of the quality of life. Most respondents recognized weight gain and general physical health as areas of insufficiency in their practical information and interactions with health care providers. Despite the ubiquity and implications of comorbid medical illnesses and medication-related adverse events, most respondents did not obtain occasional screening or observation for medical risk factors and diseases. Overall, respondents reported general dissatisfaction when interacting with mental health care providers. The author concludes that metabolic consequences of psychotropic medicine are the most concerning feature of drug treatment for patients, leading to perceived morbidity, a decrease of the quality of life, and decreased satisfaction with the treatment. Regardless of the compelling data that highlights the hazards due to comorbid physical conditions, most persons with BD take guideline-discordant treatment for somatic health illnesses as well as for the principal psychiatric disorder. Barriers to somatic health care for people with schizophrenia and $\mathrm{BD}$, as well as the effect of targeted interventions, warrant future research.

In the study of Masand and Tracy, ${ }^{13}$ weight gain from antipsychotics (33.3\%) and mood stabilizers (46.4\%) was the most problematic side effect for respondents. It is surprising that more respondents were more worried about weight gain on mood stabilizers than weight gain on antipsychotics, despite the fact that weight gain with many novel antipsychotics such as clozapine, olanzapine, and quetiapine is much more problematic than with the traditional mood stabilizers. ${ }^{63}$

Parkinsonian adverse symptoms were a primary distress in $17 \%$ of the respondents receiving antipsychotic treatment. Although the second-generation antipsychotics cause less extrapyramidal symptoms, their prevalence remains substantial. ${ }^{14}$ Clinicians need to be less accepting of extrapyramidal symptoms with the novel antipsychotics; subsequently, they can be a cause of abundant morbidity and even suicidality.

While a significant number of respondents did not answer a question about arbitrary withdrawal of medication, the second most common answer about nonadherence yielded the rate of $30 \%-70 \%$, conceivably indicating that numerous respondents themselves had been drug nonadherent. This finding is supported by a documented range of 36\%-80\% nonadherence according to Sylvia et al. ${ }^{64}$ Only $7.5 \%$ of people assumed that medication nonadherence occurred in $<20 \%$ of patients.

\section{Dosage}

Doses of medication for mania are sometimes prescribed at the upper limit of the recommended dose range and 
sometimes exceed it. This can be done not only with one drug but also with several drugs. This practice significantly increases the occurrence of side effects. High doses should be reduced for the future. However, this often does not happen because of avoiding relapse.

\section{Combinations}

Patients typically need more than one medication to maintain remission, and the practice of adding a second-generation antipsychotic to lithium, sodium valproate, and/or antidepressant is common. The drugs that target the manic and mixed episodes of BD have a stronger scientific base than those for the management of depression. ${ }^{13}$

The survey by Masand and Tracy ${ }^{13}$ showed that most patients with $\mathrm{BD}$ are taking three or more medications, and it is common $(13.3 \%)$ that patients with BD take five or more drugs. These outcomes are comparable to the results of Levine et al, ${ }^{65}$ who found that nearly $50 \%$ of study participants received three or more psychotropic drugs; polypharmacy was not linked to demographic factors such as sex, age, educational or marital status, or medication prescriptions.

\section{Implications for psychotherapy}

Psychoeducation and approaches such as interpersonal therapy and cognitive behavioral therapy (CBT) have been shown to decrease relapse and recurrence rates significantly when added to medication in patients with BD. ${ }^{66-68}$ Unfortunately, they are underutilized because of the lack of trained therapists, cost, and compensation issues. The addition of CBT to treatment as usual (TAU) was supposed to be cost-effective because of decreases in using of services. ${ }^{66}$

Individual CBT for BD builds on Beck's cognitive therapy; a skills-based therapy supports people in identifying and changing the association between maladaptive beliefs and moods. Using mood diaries, activity scheduling, and thought records, BD patients learn to change automatic negative thoughts, eliminate distorted thinking, and block episodes of mania and depression. ${ }^{69}$

Lam et $a l^{67}$ randomized $103 \mathrm{BD}$ patients with a history of recurrent episodes (at least two episodes in 2 years or three episodes in 5 years) to individual CBT or TAU. CBT was managed as 12-18 meetings over 6 months followed by two booster sessions. The risk of relapse was significantly lower in the CBT compared with TAU over 12 months. Those allocated to CBT also had lower rates of relapse compared with TAU (64\% vs 84\%) and a longer time to the depressive episode than TAU over 30 months follow-up.
Group CBT, while not as extensively verified as individual $\mathrm{CBT}$, has confirmed effectiveness for BD. The study of Williams et $\mathrm{al}^{70}$ summarized earlier exhibited greater outcomes to TAU on measures of depressive and anxiety symptoms, functioning, and time to relapse. Several findings advocate that group CBT would be a valuable addition to pharmacotherapy for the treatment of BD. ${ }^{71-73}$

\section{Conclusion}

Overlooking taking of prescribed drugs and difficulties with adverse effects are major impediments to treatment. The absence of medication schedules, uncooperative social systems, lack of illness understanding, and treatment complications may also affect overall adherence. Yet, there are various unmet needs in the management of BD. Moreover, there are discrepancies among the evidencebased treatments for $\mathrm{BD}$ and patient perception of the relative effectiveness of different drugs. There is a need to arrange for psychiatrists, patients, and patients' families better psychoeducation about the best evidence-based treatments for BD.

\section{Disclosure}

The authors proclaim that the article was written without any profitable or financial relations that could be understood as a possible conflict of interest. The authors report no other conflicts of interest in this work.

\section{References}

1. U. S. Public Health Service Office of the Surgeon General. Mental Health: Culture, Race, and Ethnicity: A Supplement to Mental Health: A Report of the Surgeon General. Rockville, MD: Department of Health and Human Services, U.S. Public Health Service; 2001.

2. Torres-González F, Ibanez-Casas I, Saldivia S, et al. Unmet needs in the management of schizophrenia. Neuropsychiatr Dis Treat. 2014;10: 97-110.

3. Van der Voort TY, Goossens PJ, van der Bijl JJ. Alone together: a grounded theory study of experienced burden, coping, and support needs of spouses of persons with a bipolar disorder. Int J Ment Health Nurs. 2009; 18(6):434-443.

4. Van der Voort TYG, Goossens PJJ, van der Bijl JJ. Coping, burden, and needs for support of caregivers of persons with bipolar disorder: a systematic review. J Psychiatr Ment Health Nurs. 2007;14(7):679-687.

5. Karp DA, Tanarugsachock V. Mental illness, caregiving, and emotion management. Qual Health Res. 2000;10(1):6-25.

6. Lam D, Donaldson C, Brown Y, Malliaris Y. Burden and marital and sexual satisfaction in the spouses of bipolar patients. Bipolar Disord. 2005; 7(5):431-440.

7. Perlick DA, Rosenheck RA, Miklowitz DJ, et al. Prevalence and correlates of burden among caregivers of patients with bipolar disorder enrolled in the systematic treatment enhancement program for bipolar disorder. Bipolar Disord. 2007;9(3):262-273.

8. Chengappa KR, Williams P. Barriers to the effective management of bipolar disorder: a survey of psychiatrists based in the UK and USA. Bipolar Disord. 2005;7(suppl 1):38-42. 
9. Kulkarni J, Filia S, Berk L, et al. Treatment and outcomes of an Australian cohort of outpatients with bipolar I or schizoaffective disorder over twenty-four months: implications for clinical practice. BMC Psychiatry. 2012;12(1):228.

10. Judd LL, Akiskal HS, Schettler PJ, et al. The long-term natural history of the weekly symptomatic status of bipolar I disorder. Arch Gen Psychiatry. 2002;59(6):530-537.

11. Cuijpers P, Stam H. Burnout among relatives of psychiatric patients attending psychoeducational support groups. Psychiatr Serv. 2000; 51(3):375-379.

12. Bauer MS, Kilbourne AM, Ludman E, Greenwald D. Overcoming Bipolar Disorder: A Comprehensive Workbook for Managing Your Symptoms and Achieving Your Life Goals. Oakland, CA: New Harbinger Publications, Inc; 2008.

13. Masand PS, Tracy N. Results from an online survey of patient and caregiver perspectives on unmet needs in the treatment of bipolar disorder. Prim Care Companion CNS Disord. 2014 Aug 28;16(4). doi: 10.4088/ PCC.14m01655. eCollection 2014.

14. Leibenluft E, Clark CH, Myers FS. The reproducibility of depressive and hypomanic symptoms across repeated episodes in patients with rapid-cycling bipolar disorder. J Affect Disord. 1995;33(2): 83-88.

15. Schaffer A, McIntosh D, Goldstein BI, et al. Canadian Network for Mood and Anxiety Treatments (CANMAT) Task Force: The CANMAT task force recommendations for the management of patients with mood disorders and comorbid anxiety disorders. Ann Clin Psychiatry. 2012;24(1):6-22.

16. Latalova K, Prasko J, Grambal A, et al. Bipolar disorder and anxiety disorders. Neuro Endocrinol Lett. 2013;34(8):738-744.

17. Latalova K, Ociskova M, Prasko J, Kamaradova D, Jelenova D, Sedlackova Z. Self-stigmatization in patients with bipolar disorder. Neuro Endocrinol Lett. 2013;34(4):265-272.

18. Hajda M, Kamaradova D, Latalova K, et al. Self-stigma, treatment adherence, and medication discontinuation in patients with bipolar disorders in remission - a cross-sectional study. Act Nerv Super Rediviva. 2015; 57(1-2):6-11.

19. Westermann S, Cavelti M, Heibach E, Caspar F. Motive-oriented therapeutic relationship building for patients diagnosed with schizophrenia Front Psychol. 2015;6:1294.

20. MacQueen GM, Marriott M, Begin H, Robb J, Joffe RT, Young LT. Subsyndromal symptoms assessed in longitudinal, prospective follow-up of a cohort of patients with bipolar disorder. Bipolar Disord. 2003; 5(5):349-355.

21. Gerson LD, Rose LE. Needs of persons with serious mental illness following discharge from inpatient treatment: patient and family views. Arch Psychiatr Nurs. 2012;26(4):261-271.

22. Gitlin MJ, Swendsen J, Heller TL, Hammen C. Relapse and impairment in bipolar disorder. Am J Psychiatry. 1995;152(11):1635-1640.

23. Ancoli-Israel S, Roth T. Characteristics of insomnia in the United States: results of the 1991 National Sleep Foundation Survey I. Sleep. 1999;22(suppl 2):S347-S353.

24. Jackson A, Cavanagh J, Scott J. A systematic review of manic and depressive prodromes. J Affect Disord. 2003;74(3):209-217.

25. Harvey AG. Sleep and circadian rhythms in bipolar disorder: seeking synchrony, harmony, and regulation. Am J Psychiatry. 2008;165(7): 820-829.

26. Millar A, Espie CA, Scott J. The sleep of remitted bipolar outpatients: a controlled naturalistic study using actigraphy. J Affect Disord. 2004; $80(2-3): 145-153$.

27. Harvey AG, Schmidt DA, Scarnà A, Semler CN, Goodwin GM. Sleeprelated functioning in euthymic patients with bipolar disorder, patients with insomnia, and subjects without sleep problems. Am J Psychiatry. 2005;162(1):50-57.

28. Perry A, Tarrier N, Morriss R, McCarthy E, Limb K. Randomized controlled trial of efficacy of teaching patients with bipolar disorder to identify early symptoms of relapse and obtain treatment. BMJ. 1999; 318(7177):149-153.
29. Malkoff-Schwartz S, Frank E, Anderson B, et al. Stressful life events and social rhythm disruption in the onset of manic and depressive bipolar episodes: a preliminary investigation. Arch Gen Psychiatry. 1998; 55(8):702-707.

30. Benazzi F. Symptoms of depression as possible markers of bipolar II disorder. Prog Neuropsychopharmacol Biol Psychiatry. 2006;30(3): 471-477.

31. Bowden CL. A different depression: clinical distinctions between bipolar and unipolar depression. J Affect Discord. 2005;84(2): $117-125$.

32. Kaplan KA, Gruber J, Eidelman P, Talbot LS, Harvey AG. Hypersomnia in inter-episode bipolar disorder: does it have prognostic significance? J Affect Disord. 2011;132(3):438-444.

33. Wirz-Justice A, Benedetti F, Berger M, et al. Chronotherapeutics (light and wake therapy) in affective disorders. Psychol Med. 2005;35(7): 939-944.

34. Shattell MM, Starr SS, Thomas SP. 'Take my hand, help me out': mental health service recipients' experience of the therapeutic relationship. Int J Ment Health Nurs. 2007;16(4):274-284.

35. Nawková L, Nawka A, Adámková T, et al. The picture of mental health/ illness in the printed media in three central European countries. $J$ Health Commun. 2012;17(1):22-40.

36. Schulze B, Angermeyer MC. Subjective experiences of stigma: a focus group study of schizophrenic patients, their relatives, and mental health professionals. Soc Sci Med. 2003;56(2):299-312.

37. Link BG, Struening EL, Neese-Todd S, Asmussen S, Phelan JC. Stigma as a barrier to recovery: the consequences of stigma for the selfesteem of people with mental illnesses. Psychiatr Serv. 2001;52(12): 1621-1626.

38. Lecomte T, Laferrière-Simard MC, Leclerc C. What does the alliance predict in group interventions for early psychosis? J Contemp Psychother. 2012;42(2):55-61.

39. American Psychiatric Association (APA). Practice guideline for the treatment of patients with bipolar disorder (revision). Am J Psychiatry. 2002;159(4 Suppl):1-50.

40. Yatham LN, Kennedy SH, O'Donovan C, et al. Canadian Network for Mood and Anxiety Treatments (CANMAT) Guidelines for the management of patients with bipolar disorder: consensus and controversies. Bipolar Disord. 2005;7(suppl 3):5-69.

41. Doubek P, Prasko J, Masopust J. Bipolarni afektivni porucha (manicka, smisena a depresivni [Bipolar affective disorder (manic, mixed, and depressive)]. In: Raboch J, Uhlikova P, Hellerova P, Anders M, Susta M, editors. Doporučené postupy psychiatrické péče. Praha: Ceska psychiatricka spolecnost; 2014:82-98.

42. Regeer EJ, ten Have M, Rosso ML, Vollebergh W, Nolen WA. Prevalence of bipolar disorder in the general population: a reappraisal study of the Netherlands mental health survey and incidence study. Acta Psychiatr Scand. 2004;110(5):374-382.

43. Sajatovic M, Levin J, Fuentes-Casiano E, Cassidy KA, Tatsuoka C, Jenkins JH. Illness experience and reasons for nonadherence among individuals with bipolar disorder who are poorly adherent with medication. Compr Psychiatry. 2011;52(3):280-287.

44. Rose L. Benefits and limitations of professional-family interactions: the family perspective. Arch Psychiatr Nurs. 1998;12(3):140-147.

45. Veltman A, Cameron JI, Stewart DE. The experience of providing care to relatives with chronic mental illness. J Nerv Ment Dis. 2002;190(2): $108-114$.

46. Bruffaerts R, Sabbe M, Demyttenaere K. Effects of patient and healthsystem characteristics on community tenure of discharged patients. Psychiatr Serv. 2004;55(6):685-690.

47. Irmiter C, McCarthy JF, Barry KL, Soliman S, Blow F. Reinstitutionalization following psychiatric discharge among VA patients with serious mental illness: a national longitudinal study. Psychiatr Q. 2007;78(4): $279-286$.

48. Flückiger C, Del Re AC, Wampold BE, Symonds D, Horvath AO. How central is the alliance in psychotherapy? A multilevel longitudinal meta-analysis. J Couns Psychol. 2012;59(1):10-17. 
49. Lingam R, Scott J. Treatment non-adherence in affective disorders. Acta Psychiatr Scand. 2002;105(3):164-172.

50. Berk M, Berk L, Castle D. A collaborative approach to the treatment alliance in bipolar disorder. Bipolar Disord. 2004;6(6):504-518.

51. Sajatovic M, Jenkins JH, Cassidy KA, Muzina DJ. Medication treatment perceptions, concerns, and expectations among depressed individuals with type I bipolar disorder. J Affect Disord. 2009;115(3):360-366.

52. Clatworthy J, Bowskill R, Rank T, Parham R, Horne R. Adherence to medication in bipolar disorder: a qualitative study exploring the role of patients' beliefs about the condition and its treatment. Bipolar Disord. 2007;9(6):656-664.

53. Darling CA, Olmstead SB, Lund VE, Fairclough JF. Bipolar disorder: medication adherence and life contentment. Arch Psychiatr Nurs. 2008; 22(3):113-126.

54. Sachs GS. Psychosocial interventions as adjunctive therapy for bipolar disorder. J Psychiatr Pract. 2008;14(suppl 2):39-44.

55. Zeber JE, Copeland LA, Good CB, Fine MJ, Bauer MS, Kilbourne AM. Therapeutic alliance perceptions and medication adherence in patients with bipolar disorder. J Affect Disord. 2008;107(1-3):53-62.

56. Loebel A, Cucchiaro J, Silva R, et al. Lurasidone monotherapy in the treatment of bipolar I depression: a randomized, double-blind, placebocontrolled study. Am J Psychiatry. 2014;171(2):160-168.

57. Rea MM, Miklowitz DJ, Thompson MC, Goldstein MJ, Hwang S, Mintz J. Family-focused treatment versus individual treatment for bipolar disorder: results of a randomized clinical trial. $J$ Consult Clin Psychol. 2003;71(3):482-492.

58. Greenberg JS, Kim HW, Greenley JR. Factors associated with subjective burden in siblings of adults with severe mental illness. Am J Orthopsychiatry. 1997;67(2):231-241.

59. Perlick DA, Clarkin JF, Sirey J, Greenfield P, Struening S, Rosenheck R. Burden experienced by caregivers of persons with bipolar affective disorder. Br J Psychiatry. 1999;175(7):56-62.

60. Chakrabarti S, Gill S. Coping and its correlates among caregivers of patients with bipolar disorder: a preliminary study. Bipolar Disord. 2002; 4(1):50-60.

61. Nehra R, Chakrabarti S, Kulhara PL, Sharma R. Caregiver-coping in bipolar disorder and schizophrenia. Soc Psychiatry Psychiatr Epidem. 2005;40(4):329-336.
62. McIntyre RS. Understanding needs interactions, treatment, and expectations among individuals affected by bipolar disorder or schizophrenia: the UNITE global survey. J Clin Psychiatry. 2009;70(suppl 3):5-11.

63. Hasnain M, Vieweg WV. Weight considerations in psychotropic drug prescribing and switching. Postgrad Med. 2013;125(5):117-129.

64. Sylvia LG, Reilly-Harrington NA, Leon AC, et al. Medication adherence in a comparative effectiveness trial for bipolar disorder. Acta Psychiatr Scand. 2014;129(5):359-365.

65. Levine J, Chengappa KN, Brar JS, et al. Psychotropic drug prescription patterns among patients with bipolar I disorder. Bipolar Disord. 2000;2(2):120-130.

66. Lam DH, Hayward P, Watkins ER, Wright K, Sham P. Relapse prevention in patients with bipolar disorder: cognitive therapy outcome after 2 years. Am J Psychiatry. 2005;162(2):324-329.

67. Lam DH, Watkins ER, Hayward P, et al. A randomized controlled study of cognitive therapy for relapse prevention for bipolar affective disorder: outcome of the first year. Arch Gen Psychiatry. 2003;60(2):145-152.

68. Vieta E, Pacchiarotti I, Valentí M, Berk L, Scott J, Colom F. A critical update on psychological interventions for bipolar disorders. Curr Psychiatry Rep. 2009;11(6):494-502.

69. Beck AT, Rush AJ, Shaw BF, Gary E. Cognitive Therapy of Depression. New York, NY: Guilford Press; 1979.

70. Williams JM, Alatiq Y, Crane C, et al. Mindfulness-based cognitive therapy (MBCT) in bipolar disorder: preliminary evaluation of immediate effects on between-episode functioning. $J$ Affect Disord. 2008; 107(1-3):275-279.

71. Costa RT, Cheniaux E, Rosaes PA, et al. The effectiveness of cognitive behavioral group therapy in treating bipolar disorder: a randomized controlled study. Rev Bras Psiquiatr. 2011;33(2):144-149.

72. Gomes BC, Abreu LN, Brietzke E, et al. A randomized controlled trial of cognitive behavioral group therapy for bipolar disorder. Psychother Psychosom. 2011;80(3):144-150.

73. González Isasi A, Echeburúa E, Limiñana JM, González-Pinto A. Psychoeducation and cognitive-behavioral therapy for patients with refractory bipolar disorder: a 5-year controlled clinical trial. Eur Psychiatry. 2014;29(3):134-141.
Neuropsychiatric Disease and Treatment

\section{Publish your work in this journal}

Neuropsychiatric Disease and Treatment is an international, peerreviewed journal of clinical therapeutics and pharmacology focusing on concise rapid reporting of clinical or pre-clinical studies on a range of neuropsychiatric and neurological disorders. This journal is indexed on PubMed Central, the 'PsycINFO' database and CAS,

\section{Dovepress}

and is the official journal of The International Neuropsychiatric Association (INA). The manuscript management system is completely online and includes a very quick and fair peer-review system, which is all easy to use. Visit http://www.dovepress.com/testimonials.php to read real quotes from published authors. 